\title{
Diphenyl diselenide, a simple glutathione peroxidase mimetic, inhibits human LDL oxidation in vitro
}

\author{
Andreza Fabro de Bem ${ }^{\mathrm{a}, *}$, Marcelo Farina ${ }^{\mathrm{a}}$, Rafael de Lima Portella ${ }^{\mathrm{b}}$, \\ Cristina Wayne Nogueira ${ }^{b}$, Teresa C.P. Dinis ${ }^{c}$, \\ João A.N. Laranjinha ${ }^{\mathrm{c}}$, Leonor M. Almeida ${ }^{\mathrm{c}}$, \\ João Batista Teixeira Rocha ${ }^{b}$

\footnotetext{
a Departamento de Bioquímica, Centro de Ciências Biológicas, Universidade Federal de Santa Catarina, Florianópolis, SC 88040900, Brazil

b Departamento de Química, Centro de Ciências Naturais e Exatas, Universidade Federal de Santa Maria, Santa Maria, RS 97105900, Brazil

${ }^{\mathrm{c}}$ Laboratório de Bioquímica, Faculdade de Farmácia, Universidade de Coimbra, Coimbra 3000, Portugal
} \\ Received 29 August 2007; received in revised form 27 February 2008; accepted 29 February 2008
}

\begin{abstract}
Oxidative modification of low-density lipoprotein (LDL) represents an important factor in atherogenesis. In the present study, we have investigated the antioxidant capability of diphenyl diselenide $(\mathrm{PhSe})_{2}$, a simple organoseleno compound, against copper $\left(\mathrm{Cu}^{2+}\right)$ and peroxyl radical-induced human LDL oxidation in vitro. In initial studies using human serum, $(\mathrm{PhSe})_{2}$ caused a dose-dependent inhibition of $\mathrm{Cu}^{2+}$ induced lipid peroxidation, which was correlated to thiol consumption. $(\mathrm{PhSe})_{2}$ increased lipid peroxidation lag phase and decreased lipid peroxidation rate in isolated human LDL, evaluated by measuring both conjugated diene (CD) and thiobarbituric acid reactive substances (TBARS) levels. Consistent with these observations, $(\mathrm{PhSe})_{2}$ showed a marked inhibitory effect on 2,2-azobis(2-amidinopropane dihydrochloride) (AAPH)-induced oxidation of LDL or parinaric acid (PnA) incorporated into LDL. $(\mathrm{PhSe})_{2}$ also displayed a dose-dependent protective effect against $\mathrm{Cu}^{2+}$-induced lipid peroxidation in rat aortic slices. Interestingly, besides the antioxidant effects of $(\mathrm{PhSe})_{2}$ toward the lipid moieties of LDL, which was related to its thiol-peroxidase activity, protein moieties from human isolated LDL were also protected against $\mathrm{Cu}^{2+}$-induced oxidation. The results presented herein are the first to show that (i) $(\mathrm{PhSe})_{2}$ inhibits lipid peroxidation in human isolated LDL in vitro, (ii) this phenomenon is related to its thiol-peroxidase activity, and (iii) this chalcogen also prevents the oxidation of protein moieties of human LDL. Taken together, such data render $(\mathrm{PhSe})_{2}$ a promising molecule for pharmacological studies with respect to the atherogenic process.
\end{abstract}

(C) 2008 Elsevier Ireland Ltd. All rights reserved.

Keywords: Diphenyl diselenide; Selenium; Ebselen; Glutathione peroxidase; LDL oxidation; Atherosclerosis

\section{Introduction}

Atherosclerosis remains the most common cause of death in industrialized countries. This affects the vascular wall and leads to coronary artery diseases and cerebrovascular accidents (stroke) [1]. There is increasing evidence that oxidative modifications of low-density lipoprotein (LDL) play a pivotal role in the development of atherosclerosis. Moreover, elevated levels of oxidized LDL have been positively correlated

\footnotetext{
* Corresponding author. Tel.: +55 48 37219589; fax: +55 4837219672.

E-mail address: andrezadebem@ccb.ufsc.br (A.F. Bem).
}

to the severity of acute coronary events and have been considered a biochemical marker for coronary heart disease [2].

Although the molecular bases related to the triggering process of LDL oxidation remain unclear, the major mechanisms currently explored are metal ions dyshomeostasis, changes in lipoxygenase- and myeloperoxidase-related pathways, reactive oxygen and nitrogen species generation, and alterations in the thiol status [3].

Since LDL oxidation plays a key role in the pathogenesis of atherosclerosis, antioxidants that can inhibit this oxidative process might be useful in preventing atherosclerosis-related pathological conditions, such as coronary artery diseases and 
stroke [4]. In this regard, it has been evidenced that antioxidant capability of LDL can be easily increased by dietary antioxidant supplementation. In fact, many endogenous and exogenous compounds have been reported to display beneficial effects against LDL oxidation [5].

Selenium (Se) is an essential nutrient associated with the function of major metabolic pathways in the cell, where it is incorporated as selenocysteine at the active site of a wide range of proteins [6]. Selenium intake is inversely correlated to the incidence of atherosclerosis and coronary heart disease [7]. In endothelial cells, selenium can protect from oxidative damage by altering the expression of selenoproteins which have antioxidant function, including cytoplasmic glutathione peroxidase (cyGPX), phospholipid hydroperoxide glutathione peroxidase (PHGPx) and thioredoxin reductase (TR) [8].

The interest in organoselenium chemistry and biochemistry has increased in the last three decades mainly due to the fact that several organoselenium compounds possess antioxidant activity [9], which is interplayed with its glutathione-peroxidase-like activity [10,11]. The first example of such a compound was ebselen [12,13], and this compound has been extensively studied in reason of its antioxidants and anti-inflammatory properties [14,15]. Considering the pharmacological properties of ebselen, we have been studying the pharmacological properties of another organoselenium compound, diphenyl diselenide $(\mathrm{PhSe})_{2}$, which also exhibits thiol-peroxidase-like activity which is about two times that of ebselen $[10,16]$.

This organoselenium caused minimal toxicity when administrated acutely to mice and rats [17] and after a long term exposure to rabbits $[18,19]$ and has been reported to present lower toxicity than ebselen [11]. Recently, studies from our laboratory have demonstrated that $(\mathrm{PhSe})_{2}$ caused a significant reduction in blood glucose and glycated protein levels in diabetic rats [20]. Moreover, the in vitro and in vivo antioxidant potential of $(\mathrm{PhSe})_{2}$ was already demonstrated in several tissues and models, including brain, liver and platelets $[11,21]$.

Given the earlier observations, the present study was carried out to evaluate the potential beneficial effects of $(\mathrm{PhSe})_{2}$ in protecting in vitro oxidation using different methodological approaches: human serum, human isolated LDL, and rat aortic slices (rich in endothelial cells), which are the main elements involved in the early atherosclerosis development in vivo. The thiol-peroxidase capability of $(\mathrm{PhSe})_{2}$ was also evaluated in an attempt to delve into molecular mechanisms related to the aforementioned antioxidant effects.

\section{Materials and methods}

\subsection{Materials}

Diphenyl diselenide $(\mathrm{PhSe})_{2}$ was synthesized according to a method previously described [22]. Analyses of the ${ }^{1} \mathrm{H}$
NMR and ${ }^{13} \mathrm{C}$ NMR spectra showed that the obtained compound had analytical and spectroscopic data in full agreement with its assigned structure. The chemical purity of $(\mathrm{PhSe})_{2}$ (99.9\%) was determined by GC/HPLC. (PhSe) $)_{2}$ was solubilized in ethanol PA and a 10-mM stock solution was stored at $4{ }^{\circ} \mathrm{C}$ for less than 2 weeks. Immediately before use, $(\mathrm{PhSe})_{2}$ was diluted in ethanol PA at the required concentrations for the different assays. All other chemicals were of analytical grade and obtained from standard commercial suppliers.

\subsection{Serum oxidation}

The study was approved by our Ethic Committee at Universidade Federal de Santa Maria. Blood samples were collected from healthy and normolipidemic volunteers after a 12-h overnight fasting period. Samples were left to clot in the dark at room temperature for $30 \mathrm{~min}$ and then centrifuged at $1500 \times g$ for $15 \mathrm{~min}$. The serum was removed and immediately used in the oxidation assays and oxidations were performed in serum rather than in plasma to avoid potential interferences of substances such as EDTA, heparin, or citrate. Briefly, serum samples were diluted 1:4 in $10 \mathrm{mM}$ potassium phosphate buffer, $\mathrm{pH} 7.4$ and incubated at $37^{\circ} \mathrm{C}$ with $\mathrm{CuSO}_{4}(100 \mu \mathrm{M})$ and/or $(\mathrm{PhSe})_{2}(0-200 \mu \mathrm{M})$. The total volume was $9 \mathrm{~mL}$. At different time points, aliquots $(200 \mu \mathrm{L})$ were removed for evaluating thiobarbituric acid reactive substances (TBARS) levels and consumption of the total thiol groups (-SH). Serum TBARS levels and thiol groups were determined based on Ohkawa et al. [23] and Ellman [24], respectively.

\subsection{Thiol-peroxidase activity of $(\mathrm{PhSe})_{2}$ and spectroscopy studies}

The thiol-peroxidase activity of $(\mathrm{PhSe})_{2}$ was measured according to a method previously described by Wilson et al. [10]. $(\mathrm{PhSe})_{2}(50 \mu \mathrm{M})$ was incubated at $37^{\circ} \mathrm{C}$ in a medium containing $50 \mathrm{mM}$ potassium phosphate buffer, $\mathrm{pH} 7.0,1 \mathrm{mM}$ ethylene diamine tetraacetic acid (EDTA), $1 \mathrm{mM}$ reduced glutathione (GSH), $1 \mathrm{U}$ of GR and $0.25 \mathrm{mM}$ NADPH (final volume of reaction $=1 \mathrm{~mL}$ ). The reaction was initiated by addition of $0.5 \mu \mathrm{mol}$ of hydrogen peroxide. The activity was followed by the decrease of NADPH absorption at $340 \mathrm{~nm}$. Appropriate controls were carried out without $(\mathrm{PhSe})_{2}$ and were subtracted.

In order to evaluate the potential chemical interaction between $(\mathrm{PhSe})_{2}$, GSH and $\mathrm{H}_{2} \mathrm{O}_{2}$, $(\mathrm{PhSe})_{2}(20 \mu \mathrm{M})$ was incubated with GSH $(200 \mu \mathrm{M})$ in $10 \mathrm{mM}$ potassium phosphate buffer ( $\mathrm{pH}$ 7.4). The reaction was performed at $37^{\circ} \mathrm{C}$ in a quartz cuvette and monitored spectrophotometrically (250-400 nm) using a PerkinElmer Lambda 6 spectrophotometer. In additional experiments, $\mathrm{H}_{2} \mathrm{O}_{2}(200 \mu \mathrm{M})$ was added $1 \mathrm{~min}$ after the reaction of $(\mathrm{PhSe})_{2}$ with GSH. The reaction mixture had $2 \mathrm{~mL}$. Temperature was maintained using a circulating water bath. Readings were done against a reference cuvette containing phosphate buffer. 


\subsection{LDL isolation}

LDL was isolated from fresh human plasma by discontinuous density-gradient ultracentrifugation as described by Silva et al. [25], with slight modifications. Plasma of nonfasted healthy normolipidemic donors collected with EDTA $(1 \mathrm{mg} / \mathrm{mL})$ was pooled and sucrose (final concentration, $0.5 \%$ ) was added to prevent LDL aggregation. Five milliliters of EDTA-plasma adjusted to a density of $1.22 \mathrm{~g} / \mathrm{mL}$ with solid $\mathrm{KBr}(0.326 \mathrm{~g} / \mathrm{mL})$ was layered on the bottom of a centrifuge tube. Then $5 \mathrm{~mL}$ EDTA-containing sodium chloride solution (density $1.006 \mathrm{~g} / \mathrm{mL}$ ) was overlaid on top of the plasma. Ultracentrifugation was run at $65,000 \mathrm{rpm}$ for $2 \mathrm{~h}$ at $4{ }^{\circ} \mathrm{C}$, in a Hitachi ultracentrifuge. LDL particles were collected by aspiration of the yellow band, which is located in the middle of sodium chloride solution just above the plasma main fractions. Then, $4 \mathrm{~mL}$ of LDL particles was dialyzed exhaustively overnight at $4{ }^{\circ} \mathrm{C}$ against $6 \mathrm{~L}$ of $10 \mathrm{mM}$ phosphate buffer to remove the excess salt and the majority of the EDTA. Protein concentration in LDL solution was determined by Lowry et al. [26]. The purity of LDL preparation was verified by agarose gel electrophoresis. Isolated LDL was stored at $-20^{\circ} \mathrm{C}$ not longer than 2 weeks.

\subsection{LDL oxidation}

Incubation of LDL with copper ions initiates lipid peroxidation and causes extensive oxidation of the LDL lipids. $\mathrm{Cu}^{2+}$-mediated oxidation is frequently used to assess the susceptibility of LDL to oxidation which is regarded as a possible risk factor for atherosclerosis [27].

LDL oxidation was monitored by following the CD formation and the TBARS production. LDL samples $(50 \mu \mathrm{g}$ protein $/ \mathrm{mL}$ ) were pre-incubated at $37^{\circ} \mathrm{C}$ in a medium containing $10 \mathrm{mM}$ potassium phosphate buffer, $\mathrm{pH} 7.4$ and different concentrations of $(\mathrm{PhSe})_{2}(0-40 \mu \mathrm{M})$. After $10 \mathrm{~min}$, $\mathrm{CuSO}_{4}(1.6,5$ or $10 \mu \mathrm{M})$ was added to the reaction medium and aliquots were removed at different time points for evaluating $\mathrm{CD}$ and TBARS production. In another set of experiments, $(\mathrm{PhSe})_{2}(40 \mu \mathrm{M})$ was added at different time points $(0,45$ or $90 \mathrm{~min})$ in an attempt to evaluate whether $(\mathrm{PhSe})_{2}$ could inhibit $\mathrm{Cu}^{2+}$-induced LDL oxidation once the process was started.

Potential antioxidant effects of $(\mathrm{PhSe})_{2}$ against LDL oxidation were also evaluated after the addition of an azo initiator, 2,2-azobis(2-amidinopropane dihydrochloride) (AAPH) $(1 \mathrm{mM})$, whose slow decomposition generates peroxyl radical at a constant rate in aqueous medium and induces the chain oxidation of human LDL by a free radical mediated mechanism.

In the studies of $\mathrm{CD}$ formation, the temporal change in absorbance at $234 \mathrm{~nm}$ (which refers to the CD concentration) is divided into three phases: a lag phase, a propagation phase, and a terminal phase. The lag phase was defined as the intercept of the tangent of the slope of the absorbance curve in propagation phase with the time axis, and was expressed in min. The rate of propagation was obtained from the slope of the absorbance curve during the propagation phase, and the terminal phase corresponds to the extensive oxidation of lipids of LDL. Absorbance at $234 \mathrm{~nm}$ was normalized with respect to the absorbance at the beginning of the oxidation process.

\subsection{Measurement of parinaric acid (PnA) fluorescence}

$\mathrm{PnA}$ is a polyunsaturated fatty acid that has been used successfully as a fluorescent probe to monitor the initial stages of lipid peroxidation by peroxyl radicals from AAPH [28]. Cis-PnA (9,11,13,15-octadecatetraenoic acid) fluorescence was monitored in a PerkinElmer LS 50 spectrofluorometer provided with a thermostated cuvette containing a magnetic stirring device. The excitation and emission wavelengths were 324 and $413 \mathrm{~nm}$, respectively (slit widths: $3.5 \mathrm{~nm}$ ).

Preliminary studies were performed in order to determine the concentration of LDL and PnA that insure totally incorporation of the probe into LDL and a linear fluorescent response with PnA concentration. The assays were performed at $37^{\circ} \mathrm{C}$ in $2 \mathrm{~mL}$ of potassium phosphate buffer $(110 \mathrm{mM}$ $\mathrm{NaCl}, 20 \mathrm{mM}$ phosphate, $\mathrm{pH}$ 7.4) containing $45 \mu \mathrm{g}$ of LDL protein and an aliquot of ethanolic solution of PnA (1.5 $\mu \mathrm{M}$ final concentration). The incorporation of the probe was carried out by gentle stirring for $1 \mathrm{~min}$. Increasing concentrations of $(\mathrm{PhSe})_{2}$ were added to the mixture and the oxidation reaction was initiated by addition of AAPH $(10 \mathrm{mM}$ final concentration). The capacity of (PhSe $)_{2}$ to protect LDL from oxidation was determined by the inhibition of probe fluorescence decay [28].

\subsection{Measurement of LDL-Trp fluorescence}

The time course of tryptophan (Trp) fluorescence emission intensity is used to monitor $\mathrm{Cu}^{2+}$-induced apolipoprotein LDL oxidation. The fluorescence spectra of native LDL display a single band centered at approximately $332 \mathrm{~nm}$, which is assigned to the Trp residues in apo B. Loss of Trp fluorescence is a marker for oxidations at the protein core of LDL [29]. $\mathrm{Cu}^{2+}$-induced LDL oxidation was performed in a similarly way to item described in Section 2.5, excepting that $3.3 \mu \mathrm{M}$ $\mathrm{CuSO}_{4}$ and different $(\mathrm{PhSe})_{2}$ concentrations $(0-30 \mu \mathrm{M})$ were used. Trp fluorescence was measured at different time points (0-360 min) using a Shimatzo spectrofluorometer (excitation at $282 \mathrm{~nm}$ and emission at $331 \mathrm{~nm}$ ).

\subsection{Aortic slices oxidation}

Adult Wistar rats were decapitated, thoracic aorta were quickly dissected and then removed, rinsed and submerged in a petri dish filled with ice-cold isosmotic phosphate buffer $\left(\mathrm{NaCl} 124 \mathrm{mM}, \mathrm{Na}_{2} \mathrm{HPO}_{4} 10 \mathrm{mM}, \mathrm{NaH}_{2} \mathrm{PO}_{4} 5 \mathrm{mM}\right.$, $\mathrm{KH}_{2} \mathrm{PO}_{4} 5 \mathrm{mM}$, glucose $10 \mathrm{mM}, \mathrm{pH} 7.4$ ) and cleaned of adherent fat and connective tissue in an ice-bath. Transverse propsections $(400 \mu \mathrm{m})$ were prepared using a McIlwain 
tissue chopper. Aortic slices (10 slices) were incubated in isosmotic phosphate buffer with 20 or $40 \mu \mathrm{M}$ of $(\mathrm{PhSe})_{2}$ and/or $10 \mu \mathrm{M} \mathrm{CuSO} 4$ for $2 \mathrm{~h}$. After incubations, aorta slices were washed with saline and homogenized in $400 \mu \mathrm{L}$ of acetic acid buffer ( $\mathrm{pH}$ 3.5). Lipid oxidation in aorta homogenates was measured by determining TBARS, as described by Ohkawa et al. [23]. Experimental procedures involving animals were approved by the local Animal Care Committee.

\subsection{Statistical analysis}

Values are expressed as mean \pm S.E.M. One-way analysis of variance (ANOVA) was used for multiple comparisons, followed by the Duncan's multiple range test when the $F$ value was significant. Only significant $F$-values are given in the text. Linear regression analysis was also used to test dose-dependent effects. All analyses were performed using the Statistical Package for the Social Sciences (SPSS) software in a PC-compatible computer. A value of $p<0.05$ was considered to be significant.

\section{Results}

\subsection{Effects of $(\mathrm{PhSe})_{2}$ on serum oxidation}

The protective effects of $(\mathrm{PhSe})_{2}$ against $\mathrm{Cu}^{2+}$-induced TBARS generation and thiol consumption in blood serum are depicted in Fig. 1A. $\mathrm{Cu}^{2+}(100 \mu \mathrm{M})$ caused a timedependent increase of serum TBARS levels (Fig. 1A, right, $Y$ axis) and a time-dependent decrease of total thiol groups (Fig. 1A, left, $Y$ axis). Interestingly, even though ( $\mathrm{PhSe})_{2}$ displayed a concentration-dependent inhibitory effect toward $\mathrm{Cu}^{2+}$-induced TBARS generation $\left(F_{(4,10)}=21.18 ; p<0.001\right.$; $\beta=-0.877)$, there was a stimulation of thiol groups consumption by $(\mathrm{PhSe})_{2}$.

\subsection{Spectroscopy studies}

In order to delve into molecular mechanisms involved with the beneficial role of $(\mathrm{PhSe})_{2}$ against LDL lipid peroxidation, in vitro experiments of light/UV spectroscopy concerning the chemical interaction between $(\mathrm{PhSe})_{2}, \mathrm{GSH}$ and $\mathrm{H}_{2} \mathrm{O}_{2}$ were investigated spectrophotometrically. The characteristic spectra of $20 \mu \mathrm{M}(\mathrm{PhSe})_{2}$ (line A, Fig. 1B) and of $200 \mu \mathrm{M}$ GSH (line B, Fig. 1B) was changed after their reaction (line C, Fig. 1B), probably due to the formation of phenyl selenol intermediate $\left(\mathrm{PhSe}^{-}\right)$. Interestingly, after the addition of $\mathrm{H}_{2} \mathrm{O}_{2}(200 \mu \mathrm{M})$, the strong and broad absorption peak at $270 \mathrm{~nm}$ of such intermediate was abolished, indicating its chemical interaction with $\mathrm{H}_{2} \mathrm{O}_{2}$ (Fig. 1B, spectrogram D). Consistent with this observation, $(\mathrm{PhSe})_{2}$ displayed a concentration-dependent glutathione peroxidaselike activity (Fig. 1B, inset), which was indirectly measured by NADPH consumption in the presence of GSH, purified
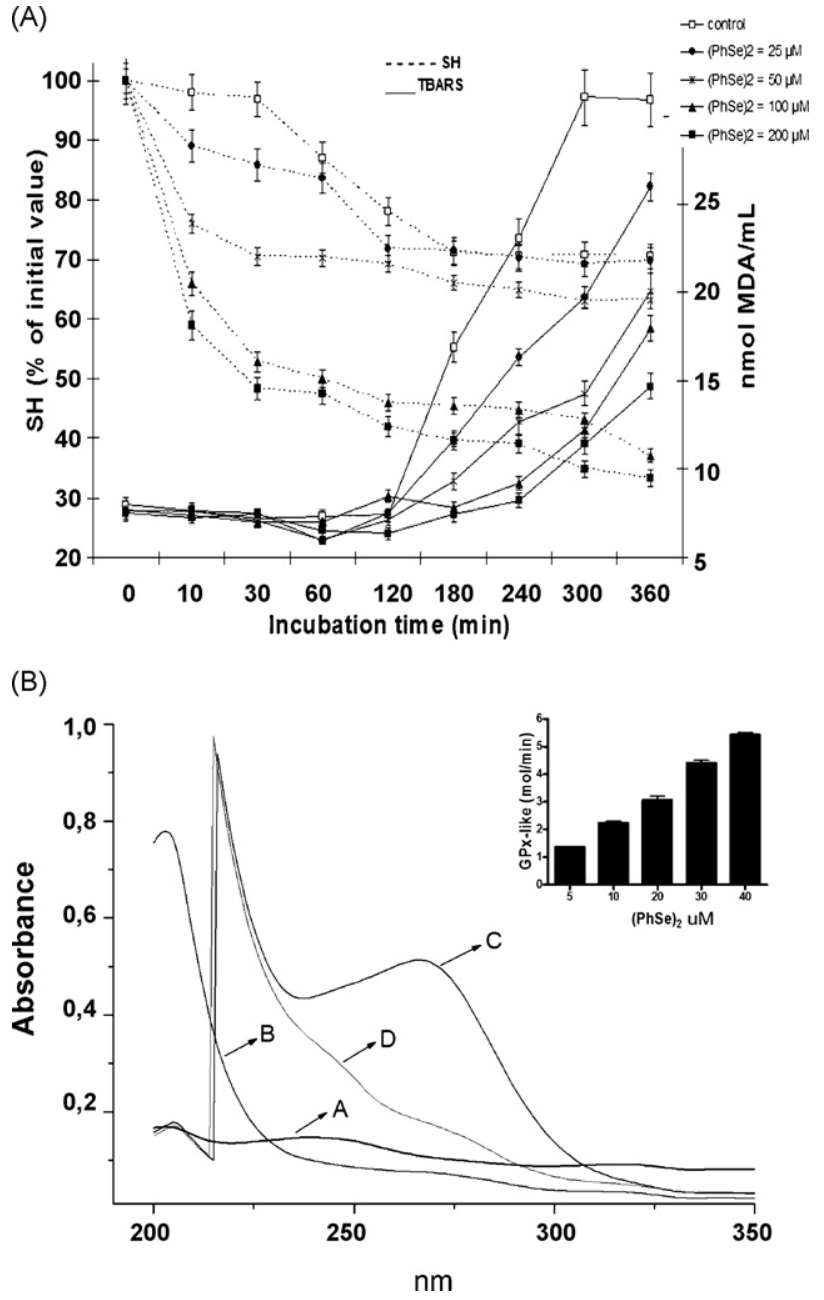

Fig. 1. (A) Effects of $(\mathrm{PhSe})_{2}$ on $\mathrm{Cu}^{2+}$-induced lipid peroxidation and thiol consumption in human serum. At different time points (indicated in the abscissa axis) TBARS (solids line) and SH (broken lines) content were analyzed (see Section 2). TBARS levels are expressed as nmol of malondialdehyde (MDA). Total thiol (-SH) content is expressed as percent of control, whose basal concentration was $437 \pm 25 \mathrm{nmol} / \mathrm{mL}$. Results are represented as mean \pm standard error of mean (S.E.M.) from at least three independent experiments. (B) The comparative spectra of $(\mathrm{PhSe})_{2}$ and the products of its interaction with GSH and/or $\mathrm{H}_{2} \mathrm{O}_{2}$. (A) $(\mathrm{PhSe})_{2}(20 \mu \mathrm{M})$; (B) $\mathrm{GSH}(200 \mu \mathrm{M})$; (C) $(\mathrm{PhSe})_{2}(20 \mu \mathrm{M})+\mathrm{GSH}(200 \mu \mathrm{M})+1$ min at $37^{\circ} \mathrm{C}$; (D) $(\mathrm{PhSe})_{2}(20 \mu \mathrm{M})+\mathrm{GSH}(200 \mu \mathrm{M})+1 \mathrm{~min}+\mathrm{H}_{2} \mathrm{O}_{2}(200 \mu \mathrm{M})+1 \mathrm{~min}$ at $37^{\circ} \mathrm{C}$. Spectra of $20 \mu \mathrm{M}(\mathrm{PhSe})_{2}$ or $200 \mu \mathrm{M} \mathrm{GSH}$ were not modified by addition of $200 \mu \mathrm{M} \mathrm{H}_{2} \mathrm{O}_{2}$. For details, see Section 2. The inset graph shows glutathione peroxidase activity of $(\mathrm{PhSe})_{2}$.

GSH reductase and hydrogen peroxide. The peroxidase-like activity of $(\mathrm{PhSe})_{2}$ was approximately twice when compared to that of ebselen (data not show), these results are in agreement with the previous study of Wilson et al. [10], where they showed that $(\mathrm{PhSe})_{2}$ is about 1.6 times more effective as GPx-mimetic than ebselen. Moreover, $(\mathrm{PhSe})_{2}$ catalytically increased GSH oxidation in the presence of $\mathrm{H}_{2} \mathrm{O}_{2}$ in a concentration-dependent manner (data not show). Taken together, these data indicate that the chemical interaction between $(\mathrm{PhSe})_{2}$ and GSH produces an intermediate that is capable of interacting with peroxides. This process allows for 
the detoxification of peroxides at the expenses of sulfhydryl groups from GSH.

\subsection{Effects of $(\mathrm{PhSe})_{2}$ on the LDL oxidation}

\subsection{1. (PhSe $)_{2}$ effects on AAPH-mediated lipid LDL oxidation}

The effects of $(\mathrm{PhSe})_{2}$ on AAPH-mediated lipid LDL oxidation is depicted in Fig. 2A. AAPH caused a significant increase of $\mathrm{CD}$ formation within time (Fig. 2A). (PhSe) $)_{2}(3-50 \mu \mathrm{M})$ showed a marked inhibitory effect on AAPH-induced lipid LDL oxidation in a concentration-dependent manner. In fact, a significant negative correlation $\left(F_{(7,16)}=83.21 ; p<0.001 ; \beta=-0.944\right)$ was observed for $(\mathrm{PhSe})_{2}$ concentrations and $\mathrm{CD}$ levels (inset Fig. 2A).

\subsection{2. (PhSe $)_{2}$ effects on PnA fluorescence}

Fig. 2B shows that low concentrations of $(\mathrm{PhSe})_{2}$ $(2-4 \mu \mathrm{M})$ caused a concentration-dependent inhibition $\left(F_{(3,8)}=684.27 ; p<0.001 ; \beta=0.215\right)$ of the fluorescence intensity decay of PnA in the presence of AAPH when compared to the control condition (absence of $\left.(\mathrm{PhSe})_{2}\right)$. The inset of Fig. 2B indicates a typical control assay where the decrease of the fluorescence of PnA following the addition of AAPH reflects its oxidative degradation.

\subsection{3. (PhSe $)_{2}$ effects on $\mathrm{Cu}^{2+}$-induced LDL oxidation}

The effects of $(\mathrm{PhSe})_{2}$ on $\mathrm{Cu}^{2+}$-induced lipid oxidation in isolated LDL are depicted in Fig. 3. (PhSe $)_{2}$ inhibited $\mathrm{Cu}^{2+}$-induced generation of both CDs (Fig. 3, left) and TBARS (Fig. 3, right) in a concentration-dependent manner. $\mathrm{Cu}^{2+}$ displayed concentration-dependent oxidative effects toward lipids, evaluated by measuring CDs (Fig. 3). LDL oxidation showed an expected oxidation pattern of an initial lag phase followed by a propagation phase and a decomposition phase (Fig. 3, left), as originally described by Esterbauer et al. [4]. Interestingly, $(\mathrm{PhSe})_{2}$ caused concentration-dependent increases in lag phase and decreases in the oxidation rate, evidenced by changes in the propagation phase slope $\left(\mathrm{Cu}^{2+} 1.6 \mu \mathrm{M}: F_{(3,8)}=104.05 ; p<0.001 ; \beta=-0.910 ; \mathrm{Cu}^{2+}\right.$ $5 \mu \mathrm{M}: F_{(3,8)}=650.72 ; p<0.001 ; \beta=-0.956 ; \mathrm{Cu}^{2+} 10 \mu \mathrm{M}$ : $\left.F_{(3,8)}=41.46 ; p<0.001 ; \beta=-0.932\right)$.

In another set of experiments, $(\mathrm{PhSe})_{2}(40 \mu \mathrm{M})$ was added at different time points $(0,45$ or $90 \mathrm{~min})$ in an attempt to evaluate whether $(\mathrm{PhSe})_{2}$ could inhibit $\mathrm{Cu}^{2+}$-induced lipid LDL oxidation once the process was started. Fig. 4A shows a significant inhibitory effect of $(\mathrm{PhSe})_{2}$ toward $\mathrm{Cu}^{2+}$-induced lipid LDL oxidation when present at the beginning of the oxidation process. Interestingly, $(\mathrm{PhSe})_{2}$ inhibited $\mathrm{Cu}^{2+}$ induced lipid LDL oxidation when added to the reaction medium at 45 and $90 \mathrm{~min}$ after the oxidation process was started.
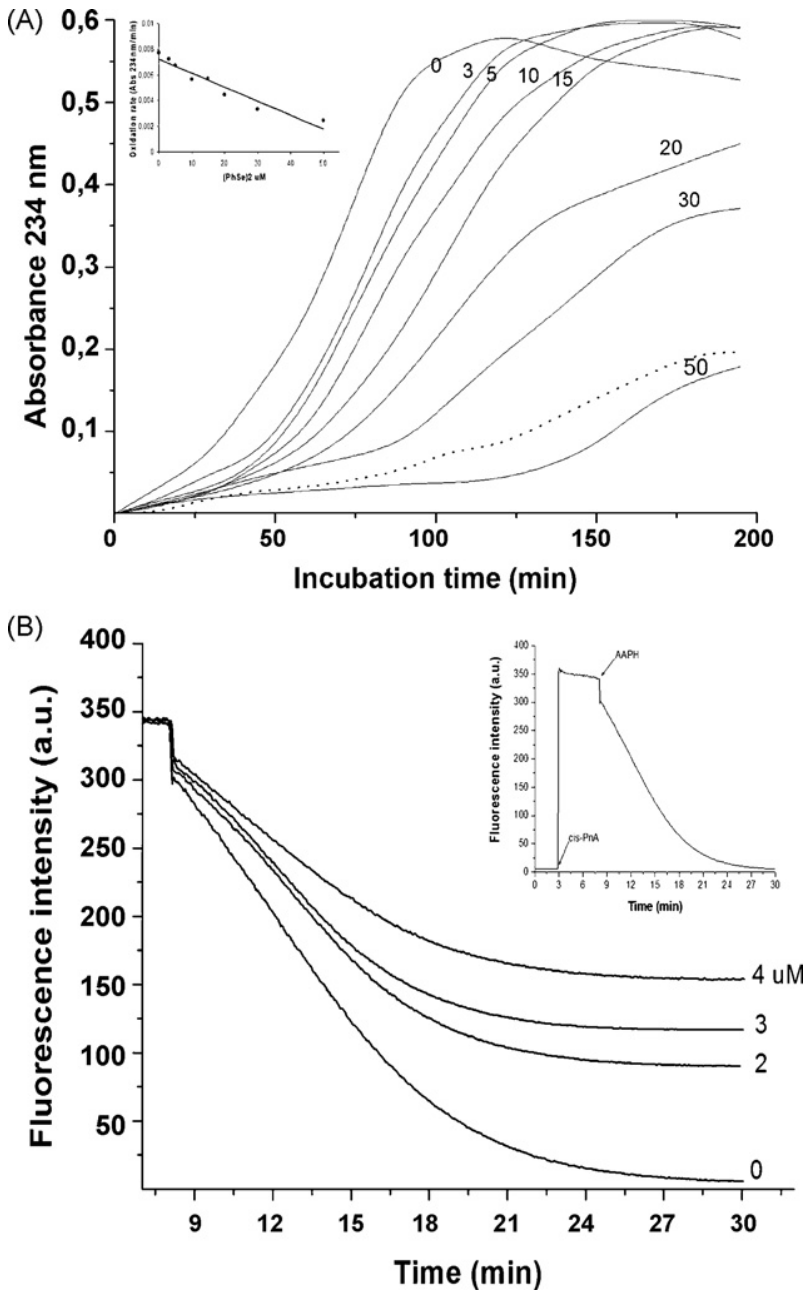

Fig. 2. (A) Effects of $(\mathrm{PhSe})_{2}$ on AAPH-induced conjugated dienes formation in human LDL. At different time points, conjugated dienes were analyzed. LDL samples $(50 \mu \mathrm{g}$ protein $/ \mathrm{mL})$ were incubated at $37^{\circ} \mathrm{C}$ with $1.0 \mathrm{mM}$ AAPH in the absence (control) or presence $(3-50 \mu \mathrm{M})$ of $(\mathrm{PhSe})_{2}$ (broken lines represent control conditions without $\mathrm{Cu}^{2+}$ addition). Conjugated dienes are expressed as absorbance at $234 \mathrm{~nm}$. Inset shows the significant correlation between oxidation rate and $(\mathrm{PhSe})_{2}$ concentrations $\left(F_{(7,16)}=83.21 ; p<0.001 ; \beta=-0.944\right)$. (B) Effect of $(\mathrm{PhSe})_{2}$ on AAPHinduced oxidation of PnA incorporated into LDL. LDL samples $(45 \mu \mathrm{g}$ protein) were incubated at $37^{\circ} \mathrm{C}$ with $1.5 \mu \mathrm{M}$ PnA for 1 min under gentle stirring. AAPH $(1.0 \mathrm{mM})$ and $(\mathrm{PhSe})_{2}(0,2,3$, or $4 \mu \mathrm{M} ; 3$ min after AAPH addition) were added to the reaction medium. Inset shows a typical control assay of PnA oxidation, incorporated into LDL, initiated by AAPH. The fluorescence intensity was recorded up to $30 \mathrm{~min}$ and shows the initial light scattering and the fluorescent signal decay following AAPH addition. Results are derived from a single representative experiment. Experiments were repeated at least three times, showing similar results

\subsection{Effects of $(\mathrm{PhSe})_{2}$ on the LDL-Trp fluorescence emission}

Fig. 4B shows that protein moieties of LDL are oxidized within time in the presence of $\mathrm{CuSO}_{4}(3.3 \mu \mathrm{M})$. This phenomenon was prevented by $(\mathrm{PhSe})_{2}$ in a concentrationdependent manner $\left(F_{(3,8)}=104.05 ; p<0.001 ; \beta=0.954\right)$. It is noteworthy that $\mathrm{Cu}^{2+}$-induced apolipoprotein LDL oxida- 

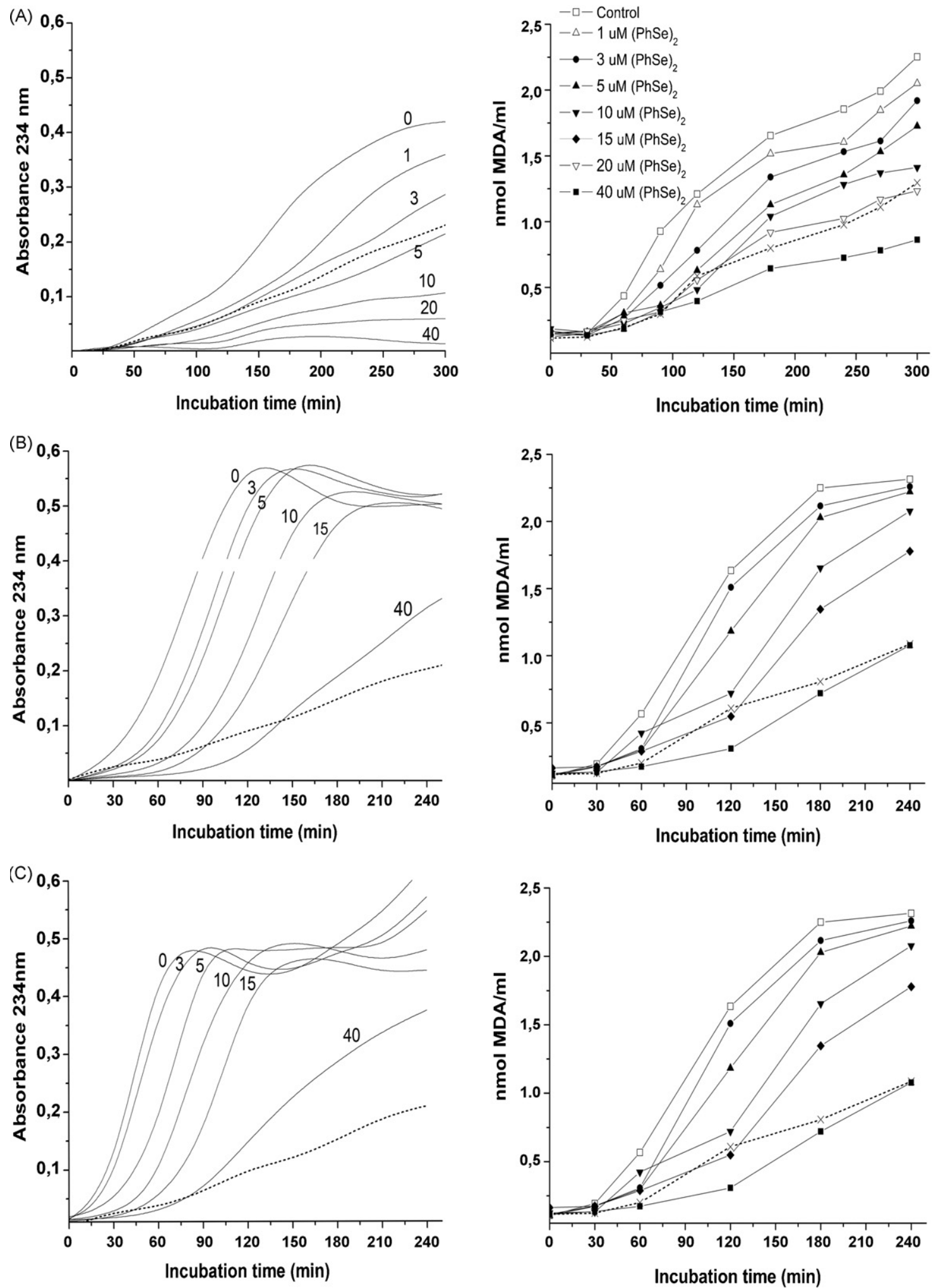

Fig. 3. Effects of $(\mathrm{PhSe})_{2}$ on $\mathrm{Cu}^{2+}$-induced lipid peroxidation in human LDL. At different time points (indicated in the abscissa axis), conjugated dienes (left) and TBARS (right) were analyzed. LDL samples $(50 \mu \mathrm{g}$ protein $/ \mathrm{mL})$ were incubated in the presence of $1.6 \mu \mathrm{M}(\mathrm{A}), 5.0 \mu \mathrm{M}(\mathrm{B})$ and $10 \mu \mathrm{M}(\mathrm{C}) \mathrm{CuSO}_{4}$ and in the absence (control) or presence $(1-40 \mu \mathrm{M})$ of $(\mathrm{PhSe})_{2}$ (broken lines represent control conditions without $\mathrm{Cu}^{2+}$ addition). TBARS levels are expressed as nmol of malondialdehyde (MDA). Conjugated dienes are expressed as absorbance at $234 \mathrm{~nm}$. Results are represented as mean \pm standard error of mean (S.E.M.) from at least three independent experiments. 

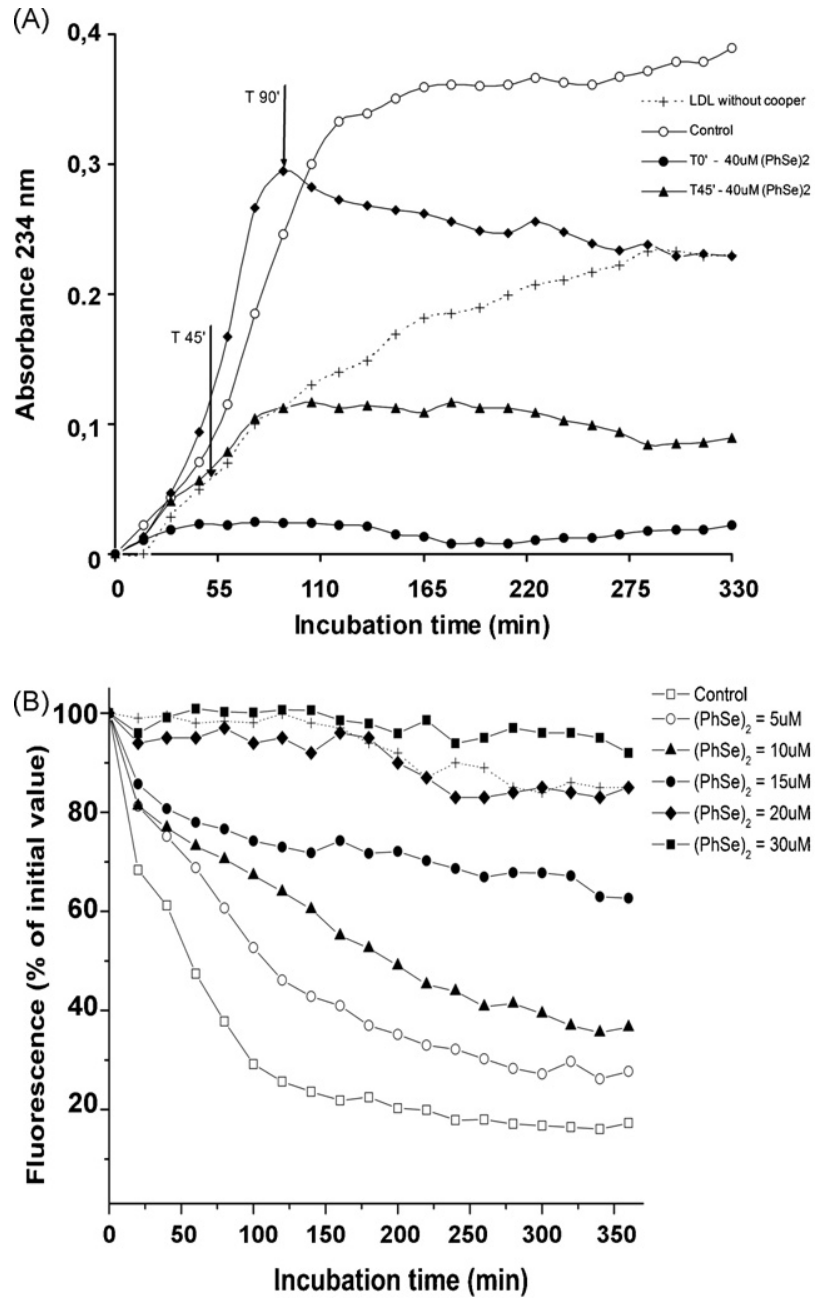

Fig. 4. (A) Effects of $(\mathrm{PhSe})_{2}$ on $\mathrm{Cu}^{2+}$-induced conjugated dienes formation in previously oxidized human LDL. LDL samples $(50 \mu \mathrm{g}$ protein $/ \mathrm{mL})$ were incubated at $37^{\circ} \mathrm{C}$ in the presence of $1.6 \mu \mathrm{M} \mathrm{CuSO}_{4}$ and in the absence (control) or presence $(40 \mu \mathrm{M})$ of $(\mathrm{PhSe})_{2}$, which was added at 0,45 or 90 min after $\mathrm{CuSO}_{4}$ addition. At different time points (indicated in the abscissa axis), conjugated dienes were analyzed. Results are expressed as absorbance at $234 \mathrm{~nm}$. Results are derived from a single representative experiment. Experiments were repeated at least three times, showing similar results. (B) Effects of $(\mathrm{PhSe})_{2}$ on $\mathrm{Cu}^{2+}$-induced loss of tryptophan fluorescence in human LDL. LDL samples $(50 \mu \mathrm{g}$ protein $/ \mathrm{mL})$ were incubated at $37^{\circ} \mathrm{C}$ in the presence of $3.3 \mu \mathrm{MCuSO}_{4}$ and different $(\mathrm{PhSe})_{2}$ concentrations $(0-30 \mu \mathrm{M})$. Tryptophan fluorescence (excitation at $282 \mathrm{~nm}$ and emission at $331 \mathrm{~nm}$ ) was measured at different time points (0-360 min) (broken lines represent control conditions without $\mathrm{Cu}^{2+}$ addition). Data are expressed as percentage of the emission intensity measured before $\mathrm{Cu}^{2+}$ addition. Results are represented as mean \pm standard error of mean (S.E.M.) from at least three independent experiments.

tion was almost completely abolished in the presence of 20 and $30 \mu \mathrm{M}$ of $(\mathrm{PhSe})_{2}$.

\subsection{Aortic slices oxidation}

The effects of $(\mathrm{PhSe})_{2}$ on $\mathrm{Cu}^{2+}$-induced lipid peroxidation in rat aortic slices are depicted in Fig. 5. One-way ANOVA showed that $10 \mu \mathrm{M} \mathrm{Cu}^{2+}$ increased $(p<0.01)$ lipid peroxida-

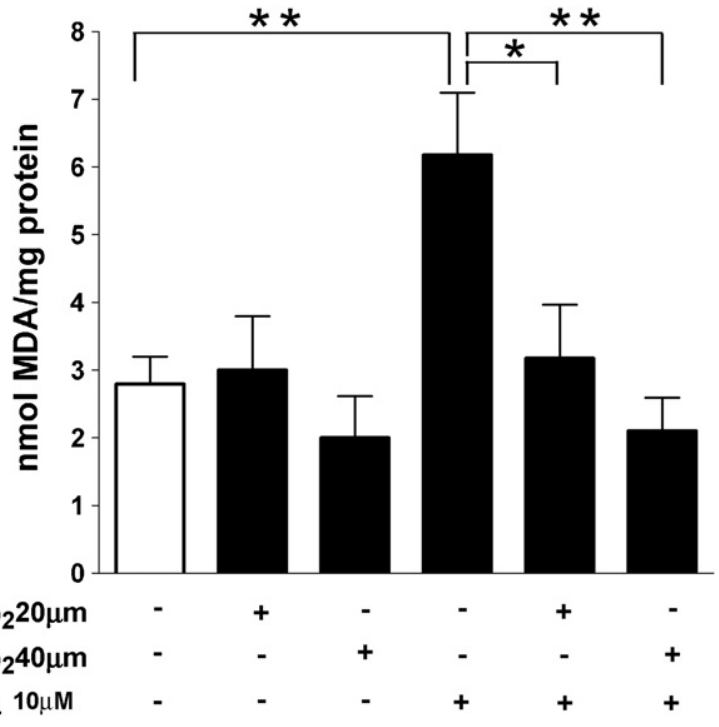

Fig. 5. Effect of $(\mathrm{PhSe})_{2}$ on $\mathrm{Cu}^{2+}$-induced lipoperoxidation in rat aortic slices. Data are expressed as nmol of malondialdehyde (MDA) per mg of protein and presented as mean \pm standard error of mean (S.E.M.) of 3-4 independent experiments. Controls are represented by an open bar. ${ }^{*} p<0.05$; $* * p<0.01$ (One-way ANOVA followed by the Duncan's multiple range test).

tion in rat aortic slices. Co-incubation of aortic rats slices with $(\mathrm{PhSe})_{2}$ for $2 \mathrm{~h}$ was associated with a reduction in lipid peroxidation induced by copper ions $\left(F_{(2,13)}=8,67 ; p<0.01\right)$. $(\mathrm{PhSe})_{2}$ was effective in decreasing $\mathrm{Cu}^{2+}$-induced TBARS formation in a concentration-dependent manner (Fig. 5; $\beta=-0.740, p<0.01)$.

\section{Discussion}

Oxidative damage to lipoproteins, in particular LDL, is known to play a role in a number of diseases associated with ageing and is in agreement with the oxidative stress theory of ageing [30]. Oxidized LDL is involved in the development of atherosclerosis through the formation of foam cells [31] and autoantibodies against oxidized LDL [32]. Since LDL oxidative damage is involved in the development of atherosclerosis, several recent studies have sought for the potential beneficial effects of antioxidant molecules against LDL oxidation [5,33]. Of particular importance, epidemiological studies have pointed to red wine polyphenols as promising molecules that could prevent the development of several coronary syndromes by inhibiting the atherogenic process [34].

There is considerable evidence suggesting that an elevated plasma copper concentration is associated with existing atherosclerosis and represents a factor of risk for disease in the future [35]. Catalytically active copper ion has been found in gruel taken from human advanced atherosclerotic lesions, indicating that the interior of human advanced atherosclerotic lesions is a highly pro-oxidant environment. Consequently, the use of copper ions to promote peroxidation of LDL under 
in vitro conditions can be considered a valid model for studying events occurring in atherosclerotic arterial wall [36]. In addition, AAPH-generated hydroxyl radical has been also reported as a good alternative for mimicking oxidative insults that occur toward lipid and protein moieties of LDL during the atherogenic process [37].

Even though several studies have reported the beneficial effects of organoseleno compounds against pathological conditions associated to oxidative stress (inflammation, gastric mucosal damage, neurotoxicity, and hepatotoxicity [11]), there are no reports regarding beneficial effects of $(\mathrm{PhSe})_{2}$ against human LDL oxidative damage. In fact, it appears that ebselen is the only organoseleno compound that has received considerable interest during the last decades $[14,15]$. In the present study, the choice for studding $(\mathrm{PhSe})_{2}$ as a potential beneficial molecule against human LDL oxidation was based on previous studies from our group, which has shown that $(\mathrm{PhSe})_{2}$ displays a higher capability of ebselen in detoxifying peroxides at expenses of sulfhydryl molecules [21].

Here, we observed that $(\mathrm{PhSe})_{2}$, an organoseleno compound with glutathione peroxidase-like activity, displayed beneficial effects against oxidation induced by copper ions or AAPH, a hydroxyl radical generator, on human serum and isolated LDL and rat aortic slices. $(\mathrm{PhSe})_{2}$ increased the oxidation lag phase and decreased the oxidation rate in isolated human LDL and these phenomena were evidenced by using different methodological approaches, including the TBARS measurement, CDs generation and incorporation of PnA into the lipoproteins.

On the other hand, $(\mathrm{PhSe})_{2}$ showed an antioxidant effect on $\mathrm{Cu}^{2+}$-induced oxidation of human serum and this effect was in a concentration-dependent manner. Moreover, this effect showed a temporal correlation with the sulfhydryl groups consumption: the increase of TBARS levels started just when stopped the decrease of SH levels $(120 \mathrm{~min})$. This phenomenon suggests the need for available reduced sulfhydryl groups for the maintenance of the beneficial effect of $(\mathrm{PhSe})_{2}$ against $\mathrm{Cu}^{2+}$-induced lipid peroxidation, reinforcing the idea of the involvement of thiol-peroxidase-like activity on the antioxidant effects of $(\mathrm{PhSe})_{2}$.

This idea is reinforced by the observed beneficial effects of $(\mathrm{PhSe})_{2}$ against the oxidation of endogenous and exogenous (incorporated PnA) LDL lipids. Inline with this, spectroscopic studies showed the direct chemical interaction between $(\mathrm{PhSe})_{2}$ and $\mathrm{GSH}$, resulting in the formation of a chemical intermediary whose stability is affected by the presence of hydrogen peroxide. Furthermore, we demonstrated a concentration-dependent antioxidant effect of $(\mathrm{PhSe})_{2}$ on $\mathrm{Cu}^{2+}$-oxidized rat aortic slices, indicating its antiatherogenic potential. Therefore, $(\mathrm{PhSe})_{2}$ behaves as a potent antioxidant in different models intimately related to the atherogenic process.

An interesting effect of this study was that $(\mathrm{PhSe})_{2}$ displayed significant beneficial effects in the different phases of $\mathrm{Cu}^{2+}$-induced LDL oxidation. In fact, when added to the reaction medium at time zero (Fig. 3A), $(\mathrm{PhSe})_{2}$ significantly prevented LDL oxidation. Moreover, when added to the reaction medium at 45 or 90 min (partially oxidized LDL), $(\mathrm{PhSe})_{2}$ was capable of stopping CDs formation. Mechanistically, these results are of interest because they indicate that the thiol-peroxidase activity of $(\mathrm{PhSe})_{2}$ is enough important to prevent the generation of secondary products of lipid peroxidation, such as CDs.

Another significant (and maybe the most important) result from our study was the capability of $(\mathrm{PhSe})_{2}$ to prevent $\mathrm{Cu}^{2+}$ induced loss of Trp fluorescence in human LDL. In this regard, it has been reported that the fluorescence spectrum of native LDL displays a single band centered at approximately $332 \mathrm{~nm}$, which is assigned to the Trp residues in apo B and loss of Trp fluorescence is a marker for oxidations at the protein core of LDL [29]. The protective effect of $(\mathrm{PhSe})_{2}$ against $\mathrm{Cu}^{2+}$-induced loss of Trp fluorescence indicates that, besides it's beneficial effects against oxidation of lipid moieties of LDL, this chalcogen also prevents the oxidation of protein moieties of human LDL, pointing to an additional mechanism that could contribute to the inhibition of the atherogenic process.

The results of the present study are the first to show that (i) $(\mathrm{PhSe})_{2}$ inhibits lipid peroxidation in human isolated LDL in vitro, (ii) this phenomenon is related to its thiol-peroxidase activity, and (iii) this chalcogen also prevents the oxidation of protein moieties of human LDL. Taken together, such data render $(\mathrm{PhSe})_{2}$ a promising molecule for pharmacological studies with respect to the atherogenic process.

\section{Acknowledgements}

The authors are grateful to Dr. Gilson Zeni to provide diphenyl disselenide for assays. The financial support by UFSM (FIPE), FAPERGS, CAPES and CNPq are gratefully acknowledged. M.F., J.B.T.R. and C.W.N. are the recipients of CNPq fellowships.

\section{References}

[1] Matsuura E, Kobayashi K, Tabuchi M, Lopez LR. Oxidative modification of low-density lipoprotein and immune regulation of atherosclerosis. Prog Lipid Res 2006;45:466-86.

[2] Witzum JL. The oxidation hypothesis of atherosclerosis. Lancet 1994;344:793-5.

[3] Halliwell B. Oxidation of low-density lipoproteins: questions of initiation, propagation, and the effect of antioxidants. Am J Clin Nutr 1995;61(Suppl. 3):670S-7S.

[4] Esterbauer H, Gebicki J, Puhl H, Jurgens G. The role of lipid peroxidation and antioxidants in oxidative modification of LDL. Free Radic Biol Med 1992;13:341-90.

[5] Noguchi N, Niki E. Phenolic antioxidants: a rationale for design and evaluation of novel antioxidant drug for atherosclerosis. Free Radic Biol Med 2000;28:1538-46.

[6] Hu ML, Tappel AL. Selenium as a sulfhydryl redox catalyst and survey of potential selenium-dependent enzymes. Inorg Biochem 1987;30:239-48. 
[7] Suadicani P, Hein HO, Gyntelberg F. Serum selenium concentration and risk of ischaemic heart disease in a prospective cohort study of 3000 males. Atherosclerosis 1992;96:33-42.

[8] Thomas JP, Geiger PG, Girotti AW. Lethal damage to endothelial cells by oxidized low density lipoprotein: role of selenoperoxidases in cytoprotection against lipid hydroperoxide- and iron-mediated reactions. J Lipid Res 1993;34:479-90.

[9] Andersson CM, Hallberg A, Linden M, et al. Antioxidant activity of some diarylselenides in biological systems. Free Radic Biol Med 1994;16:17-28.

[10] Wilson SR, Zucker PA, Huang RRC, Spector A. Development of synthetic compounds with glutathione peroxidase activity. J Am Chem Soc 1989;111:5936-9.

[11] Nogueira CW, Zeni G, Rocha JB. Organoselenium and organotellurium compounds: toxicology and pharmacology. Chem Rev 2004;104:6255-85.

[12] Müller A, Cadenas E, Graf P, Sies H. A novel biologically active seleno-organic compound. I. Glutathione peroxidase-like activity in vitro and antioxidant capacity of PZ 51 (Ebselen). Biochem Pharmacol 1984;33:3235-9.

[13] Daiber A, Zou MH, Bachschmid M, Ullrich V. Ebselen as a peroxynitrite scavenger in vitro and ex vivo. Biochem Pharmacol 2000;59:153-60.

[14] Saito I, Asano T, Sano K, et al. Neuroprotective effect of an antioxidant, ebselen, in patients with delayed neurological deficits after aneurysmal subarachnoid hemorrhage. Neurosurgery 1998;42:269-77.

[15] Yamaguchi T, Sano K, Takakura K, et al. Ebselen in acute ischemic stroke: a placebo-controlled, double-blind clinical trial. Ebselen Study Group. Stroke 1998;29:12-7.

[16] Meotti FC, Stangherlin EC, Zeni G, Nogueira CW, Rocha JB. Protective role of aryl and alkyl diselenides on lipid peroxidation. Environ Res 2004;94:276-82.

[17] Nogueira CW, Meotti FC, Curte E, et al. Investigations into the potential neurotoxicity induced by diselenides in mice and rats. Toxicology 2003;183:29-37.

[18] Bem AF, Portella RL, Perottoni J, et al. Changes in biochemical parameters in rabbits blood after oral exposure to diphenyl diselenide for long periods. Chem Biol Interact 2006;162:1-10.

[19] Bem AF, Portella RL, Farina M, et al. Low toxicity of diphenyl diselenide in rabbits: a long-term study. Basic Clin Pharmacol Toxicol 2007;101:47-55

[20] Barbosa NB, Rocha JB, Wondracek DC, et al. Diphenyl diselenide reduces temporarily hyperglycemia: possible relationship with oxidative stress. Chem Biol Interact 2006;163:230-8.

[21] Posser T, Moretto MB, Dafre AL, et al. Antioxidant effect of diphenyl diselenide against sodium nitroprusside (SNP) induced lipid perox- idation in human platelets and erythrocyte membranes: an in vitro evaluation. Chem Biol Interact 2006;164:126-35.

[22] Paulmier C. Selenium reagents and intermediates in organic synthesis. New York: Pergamon Books; 1986. p. 463

[23] Ohkawa H, Ohishi H, Yagi K. Assay for lipid peroxide in animal tissues by thiobarbituric acid reaction. Anal Biochem 1979;95:351-8.

[24] Ellman GL. Tissue sulphydryl groups. Arch Biochem Biophys 1959;82:70.

[25] Silva EL, Tsushida T, Terao J. Inhibition of mammalian 15lipoxygenase-dependent LDL lipid peroxidation by quercetin and quercetin-monoglucosides. Arch Biochem Biophys 1998;349:313-20.

[26] Lowry OH, Rosebrough NJ, Farr AL, Randall RJ. Protein measurement with the Folin phenol reagent. J Biol Chem 1951;193:265-75.

[27] Ziouzenkova O, Sevanian A, Abuja PM, Ramos P, Esterbauer H. Copper can promote oxidation of LDL by markedly different mechanisms. Free Radic Biol Med 1998;24:607-23.

[28] Laranjinha JAN, Almeida LM, Madeira VMC. Lipid peroxidation and its inhibition in low density lipoproteins: quenching of $c i s$-parinaricacid fluorescence. Arch Biochem Biophys 1992;297:147-54.

[29] Reyftmann JP, Santus R, Maziere JC, et al. Sensitivity of tryptophane and related compounds to oxidation induced by lipid autoperoxidation. Application to human low- and high-density lipoproteins. Biochim Biophys Acta 1990;1042:159-67.

[30] Stocker R, Keaney Jr JF. Role of oxidative modifications in atherosclerosis. Physiol Rev 2004;84:1381-478.

[31] Parthasarathy S, Quinn MT, Steinberg D. Is oxidized low density lipoprotein involved in the recruitment and retention of monocyte/macrophages in the artery wall during the initiation of atherosclerosis? Basic Life Sci 1988;49:375-80.

[32] Faviou E, Vourli G, Nounopoulos C, Zachari A, Dionyssiou-Asteriou A. Circulating oxidized low density lipoprotein, autoantibodies against them and homocysteine serum levels in diagnosis and estimation of severity of coronary artery disease. Free Radic Res 2005;39: 419-29.

[33] Kaliora AC, Dedoussis GVZ, Schmidt H. Dietary antioxidants in preventing atherogenesis. Atherosclerosis 2006;187:1-17.

[34] Ursini F, Sevanian A. Wine polyphenols and optimal nutrition. Ann NY Acad Sci 2002;957:200-9.

[35] Ferns GAA, Lamb DJ, Taylor A. The possible role of copper ions in atherogenesis: the Blue Janus. Atherosclerosis 1997;133:139-52.

[36] Smith C, Mitchinson MJ, Aruoma OI, et al. Stimulation of lipid peroxidation and hydroxyl-radical generation by the contents of human atherosclerotic lesions. Biochem J 1992;286:901-5.

[37] Atkin MA, Gasper A, Ullegaddi R, Powers HJ. Oxidative susceptibility of unfractionated serum or plasma: response to antioxidants in vitro and to antioxidant supplementation. Clin Chem 2005;51:2138-44. 